5. Feng J, Wang T, Wanliang Shi, et al. Identification of novel activity against Borrelia burgdorferi persisters using an FDA approved drug library. Emerg Microbes Infect 2014;3:e49.

6. National Institute of Allergy and Infectious Diseases. Chronic Lyme disease. Bethesda (MD): National Institutes of Health; 2014. Available: www.niaid.nih. gov/topics/lymeDisease/understanding/Pages/chronic. aspx (accessed 2014 Nov. 19).

7. Cameron DJ, Johnson LB, Maloney EL. Evidence assessments and guideline recommendations in Lyme disease: the clinical management of known tick bites, erythema migrans rashes and persistent disease. Expert Rev Anti Infect Ther 2014;(9): 1103-35.

8. Henry B. Lyme disease: Knowledge, beliefs, and practices of physicians in a low-endemic area. Can Fam Physician 2012;58:e289-95.

CMAJ 2015. DOI:10.1503/cmaj.115-0029

\section{Syncope confusion}

Soong and colleagues' intent was to highlight the overuse of investigations, particularly neuroimaging, among patients with syncope. ${ }^{1}$ Although Soong and colleagues cited the 2009 European Society of Cardiology guideline, ${ }^{2}$ they failed to differentiate syncope from other causes of transient loss of consciousness. Syncope is caused by global cerebral hypoperfusion, and none of the listed neurologic diagnoses cause syncope.

This confusion has led to great research efforts, consensus conferences, guidelines and statements developed by the European Society of Cardiology, the Gargnano multidisciplinary consensus conference (led by internists), and the Canadian Cardiovascular Society, all of which uniformly exclude neurologic conditions causing transient loss of consciousness from syncope..$^{2-5}$

Based on current evidence, syncope is defined as a transient loss of consciousness due to global cerebral hypoperfusion characterized by rapid onset, short duration, and spontaneous complete recovery. Sadly, this article ${ }^{1}$ worsens the confusion by clearly stating that neurologic causes of syncope exist. This could cause practising physicians to include neurologic causes in the differential diagnosis for true syncope, and to not differentiate syncope from other causes of transient loss of consciousness. This is important, as the literature evidence regarding the risk of "cardiac syncope," and use of neuroimaging exist only for true syncope patients and cannot be applied to all patients with transient loss of consciousness. The authors could also have cited new evi- dence for high-risk features for "cardiac syncope" that have been summarized, based on evidence. 6,7

\section{Venkatesh Thiruganasambandamoorthy MBBS MSc, Robert Sheldon MD PhD}

Department of Emergency Medicine (Thiruganasambandamoorthy), University of Ottawa, Ottawa, Ont.; Division of Cardiology (Sheldon), University of Calgary, Calgary, Alta.

\section{References}

1. Soong C, Chen BH, Wong BM. A 62-year-old woman with syncope. CMAJ 2015;187:48-9.

2. Moya A, Sutton R, Ammirati F, et al. Guidelines for the diagnosis and management of syncope. Eur Heart J 2009;30:2631-71.

3. Sun BC, Costantino G, Barbic F, et al. Priorities for emergency department syncope research. Ann Emerg Med 2014;64:649-55.

4. Sun BC, Thiruganasambandamoorthy V, Cruz JD. Standardized reporting guidelines for emergency department syncope risk-stratification research. Acad Emerg Med 2012;19:694-702

5. Sheldon RS, Morillo CA, Krahn AD, et al. Standardized approaches to the investigation of syncope: Canadian cardiovascular society position paper. Can J Cardiol 2011;27:246-53

6. D’Ascenzo F, Biondi-Zoccai G, Reed MJ, et al. Incidence, etiology and predictors of adverse outcomes in 43,315 patients presenting to the emergency department with syncope: An international meta-analysis. Int J Cardiol 2013;167:57-62.

7. Berecki-Gisolf J, Sheldon A, Wieling W, et al. Identifying cardiac syncope based on clinical history: A literature-based model tested in four independent datasets. PLoS ONE 2013;8:e75255.

CMAJ 2015. DOI:10.1503/cmaj.115-0030

\section{The authors respond}

We thank Thiruganasambandamoorthy and Sheldon for clarifying the definition of syncope as a transient loss of consciousness due to global cerebral hypoperfusion characterized by rapid onset, short duration and spontaneous complete recovery. ${ }^{1}$ However, experts acknowledge that this approach has pragmatic limitations, particularly when applied to undifferentiated patient presentations in the emergency department. To guide clinicians in the emergency department, our approach focuses on all potential causes of transient loss of consciousness, including syncope "mimickers." We agree that stroke, transient loss of consciousness, seizure and metabolic disturbances do not represent true syncope.

Christine Soong, MD MSc, Benjamin H. Chen, MD

Department of Medicine (Soong), University of Toronto; Division of General Internal Medicine (Soong), Mount Sinai Hospital, Toronto, Ont.; Department of
Medicine (Chen), Queen's University, Kingston, Ont.; Lennox \& Addington County General Hospital (Chen), Canadian Society of Internal Medicine (Soong, Chen), Ottawa, Ont.

\section{Reference}

1. Sun BC, Costantino G, Barbic F, et al. Priorities for emergency department syncope research. Ann Emerg Med 2014;64:649-55.

CMAJ 2015. DOI:10.1503/cmaj.115-0031

\section{Group A streptococcus}

It was gratifying to read that the authors of this commentary ${ }^{1}$ on group A streptococcus mention the significant rate of colonization versus infection. Surprisingly, this was not mentioned in the related research article. ${ }^{2}$ This continuing uncertainty, so appropriate in science, highlights the need for the art of medicine - the art in which clinicians dance with the complexity of uncertainty, balance their sense of whether the child is quite ill ("toxic") or otherwise medically fragile, converse with parents to assess their resourcefulness and preferences, and balance all of this with the public health issues. I would appreciate a review of the implications of the treatment of carrier states, with respect to group A streptococcus in particular.

Another $C M A J$ paper, ${ }^{3}$ examining the potential harms of the use of amoxicillin and amoxicillin-clavulanic acid, also surprised me by treating the two drugs as if they were similar. I understand that the latter is one of the broadest spectrum agents, and one I reserve for very specific situations. I am of the old school, and I still do not even use amoxicillin for group A streptococcus, preferring penicillin $\mathrm{V}$ (which is often not even available in the suspension form).

\section{Andre C. Piver MD}

Nelson, BC

\section{References}

1. Science M, Bitnun A, McIsaac W. Identifying and treating group A streptococcal pharyngitis in children CMAJ 2015;187:13

2. Cohen JF, Cohen R, Levy C, et al. Selective testing strategies for diagnosing group A streptococcal infection in children with pharyngitis: a systematic review and prospective multicentre external validation study. CMAJ 2015;187:23-32.

3. Gillies M, Ranakusuma A, Hoffmann T, et al. Common harms from amoxicillin: a systematic review and meta-analysis of randomized placebo-controlled trials for any indication. CMAJ 2015;187:E21-31. 